\title{
Investigating the Online Customer Experience - A B2B perspective
}

\author{
Graeme J. McLean
}

University of Strathclyde 


\section{Investigating the Online Customer Experience - A B2B perspective.}

\section{Introduction}

Researchers have developed an interest in the online customer experience, most often explored within a Business-to-Consumer (B2C) context (Hoffman; Novak, 2009; Luo et al; 2011; Rose et al, 2012). Numerous studies have outlined the web as having huge potential for B2C and B2B businesses, yet we have little understanding of what influences a customer's experience on B2B websites. Researchers, marketing practitioners and consultants have long expressed an interest in the customer experience and have agreed on its importance in producing outcomes of satisfaction, revisit intention and trust (Shobeiri et al, 2014). However, empirical research on the online customer experience (OCE) remains scant (Ahmed, 2011; Bigne et al, 2008) particularly in the B2B context (Chakraborty et al, 2002), thus it is important for both academia and industry to understand how the customer experience can affect the online customer in a number of different searching and buying contexts (Klaus, 2013).

Online social interaction through the use of web 2.0 functionality and social media has received much attention from marketing researchers as tools that allow customers to collaborate, communicate, share and connect with each other, (Kaplan; Haenlein, 2010; Mayfield, 2008; O'Reilly’s, 2005) yet limited research has explored the role of social interaction (sychronised communication) between customers and customer representatives in providing online customer support in relation to the customer experience (McLean and Wilson, 2016). Given the recent technological developments providing online communication, this paper aims to advance our understanding of the role of online communication in providing online customer support in relation to the customer experience within B2B websites.

Recently, researchers have investigated some of the drivers of a positive customer experience such as website design and ease of use (Martin et al, 2015; Trevinal, 2014). This study steps out with the online shopping environment and explores the customer experience in a B2B context, searching for business advisory information 
and services on business advisory websites. Business advisory websites provide services on business growth, leadership, developing employees, funding, tax, legal matters and day-to-day advice on running a business. Over 1 billion searches are performed for business advisory information worldwide each month (Alexa.com, 2017) making it a pertinent area of study. The main objectives of this study are (1) to examine the role of website credibility and information quality in relation to the online customer experience during a search for information on B2B websites and (2) to establish the role of online customer support through online communication in relation to a customer's experience during information search on a B2B website.

\subsection{Theoretical Background}

\section{Customer experience}

Numerous experiences are intertwined with the process of searching for information. Thus, it is important that we gain an understanding of the variables influencing the customer experience during information seeking. The customer experience has been extensively discussed in the offline environment (Schmitt, 1999; Edvardsson et al, 2005). Meyer and Schwager's (2007) suggest the customer experience is the "internal and subjective response that customers have to any direct or indirect contact with a company". However, unlike the B2C customer experience, the B2B customer experience may not be a thrilling experience, but one that is trouble-free to the business as well as being re-assuring (Meyer and Schwager, 2007). The customer experience is often theorised as a psychological construct, which is holistic and the subjective response resulting from touch-points with an organisation (Gentile et al, 2007). The psychological constructs of cognition and affect have been identified in numerous aspects of customer experience (Edvardsson, 2005),

According to Carbone and Haeckel (1994) the outcome of a customer experience is the creation of takeaway impressions that are subsequently stored in the memory of the customer. Numerous research studies have outlined that the customer experience is an important area of research due to the outcomes of a positive customer experience (Meyer; Schwager, 2007), namely satisfaction, trust, re-visit intention, re-purchase intention and loyalty (Schmitt, 1999; Edvardsson, 2005). Verhoef et al (2009) outline 
that a focus on the customer experience is of the upmost importance to organisations in order to have a competitive advantage, moving beyond that of assessing service quality.

\section{Online Customer Experience}

Empirical research on the online customer experience remains somewhat limited, particularly within the B2B domain. Customers operating in the online environment encounter numerous components capable of influencing their experience with the website (McLean and Wilson, 2016, Martin et al, 2015; Rose et al, 2012, Hoffman and Novak, 2009). Genitle et al (2007) found that customers interpret different types of information on a website (text, imagery, video and audio) from both a cognitive and affective perspective with each format having an influence on the customer's online experience. Novak et al (2000) research suggested that customers are only influenced by their cognitive thoughts online. However, subsequent research (Klaus, 2013; Rose et al, 2012; Wang et al, 2012; Verhoef et al, 2009; Ethier et al, 2006) outline emotions as playing a significant role with regard to the customer experience. As a result, Rose et al (2012, p.309) suggest that the online customer experience is a "psychological state manifested as a subjective response to the website". Therefore, the customer can be seen as engaging in cognitive and affective processing due to the influence of stimulus material and characteristics of a website, which as a result forms an impression in the memory of the customer.

A comprehensive review of the literature outlines numerous variables capable of influencing the customer experience including, website aesthetics, ease of use, customisation, interactivity, engagement, enjoyment and flow (Martin et al, 2015; Trevinal and Stenger, 2014; Rose et al, 2012; Hoffman and Novak, 2009), however two variables have been overlooked with regard to their influence on the online customer experience, namely 'Information Quality' and 'Website Credibility'. Due to the non-thrilling experience expected in the B2B context as elaborated by Meyer and Schwager (2007) it is important to investigate the potential influence of each these 'utilitarian' type variables on the customer's online experience. 


\section{Information search}

Within the area of marketing, research to date has somewhat neglected information search. Most research papers have been aiming to understand a customer's overall decision-making process in the context of purchasing a product (Engel et al, 1978). Within Engel et al's (1978) decision-making model, information search is a key part of the decision making process. Thus, it is important that marketers have an understanding of the underlying information search process. Information seeking is often seen as a complex and overwhelming process involving a significant level of uncertainty (Mills et al, 2013). Information seeking behaviour has been researched by numerous information scientists including, Dervin (1983), Belkin (1980), Taylor (1968), Ellis (1989), Kuhlthau (1991) and Wilson (1981) amongst many others. Wilson (2000) defines information behaviour as, 'the totality of human behaviour in relation to sources and channels of information, including both active and passive information seeking and information use.' Additionally, Pettigrew et al (2001) refer to information behaviour as, 'the study of how people need, seek, give and use information in different contexts, including the workplace and everyday living.'

Previous research suggests that information-seeking behaviour occurs as a consequence of a need, or an information problem perceived by an individual. In order to satisfy such a need, the individual, 'makes demands upon formal or informal information sources or services, which result in success or failure to find relevant information' (Wilson, 1999). If successful, the individual then uses the information found and may either fully or partially satisfy the perceived need or, on the contrary, may fail to satisfy the need and have to reiterate the search process. Additionally, Mclean and Wilson (2016) highlight the time conscious nature of individuals during information search in a B2B context, illustrating that individuals who are unable to find information in a timely manner will abandon their search process.

Kuhlthau's (1991) Information Search Process model offers stages that individuals go through during information seeking and highlights how the process develops over an extended period of time (Hearst, 2009). These stages include cognitive thinking, affective feelings as well as the physical aspect associated with collecting the information (Savolainen, 2015). The Information Search Process model (ISP), being 
one of the most highly cited models in the field of information science is argued as an important model for understanding both day-to-day and complex information seeking tasks (Wilson, 1999; Wiley and Williams, 2015). Kuhlthau's (2004) continually developed ISP model was revolutionary in that it combined both the cognitive and affective aspects of information search.

Kuhlthau (2004) suggests that 7 stages exist in information seeking, namely, 'Initiation' of the search, 'Selection' of the topic to search for, 'Exploration' of the area, 'Formulation' of some information and beginning to gain a focus, 'Collection' of the information, 'Presentation' of the information and finally 'Evaluation' of the success of the search. Like the customer experience, information search is regarded as a holistic process, involving the psychological constructs of cognition and affect (Kuhlthau, 1991). Kuhlthau's (1991) research was the first to outline the role of emotions in searching for information. More recent research conducted by FlavianBlanco et al (2010) found that emotions are prevalent when searching in the online environment prior, during and post search. Kuhltahu's (2004) influential research suggests that if customers do not have positive emotions during search and instead experience emotions of frustration, anxiety, uncertainty and experience dissatisfaction, they are likely to abandon their search. Thus, the research hypothesises that:

H1 A successful information search is positively related to satisfaction with the experience.

\section{Information Quality}

Information quality online is often associated with accuracy, relevance, how current and the usefulness of information provided on a website (Guo et al, 2012; Flanagin and Metzger, 2000). Kim and Park (2003) define online information quality as how customers perceive the quality of the information provided by a website.

Kateranttanakul (2002) suggests that the reliability of the content on a website can have an influence on a customer's disposition to trust and perceive lower risks and thus help the customer to make a decision, in turn having an influence on the customer's level of satisfaction. According to Guo et al (2012) this is in line with Daft 
and Lengel's (1986) Media Richness Theory that stresses the importance of the quality, reliability and accuracy of information exchanged through a particular medium. Christy and Matthew (2005) and Lui et al (2008) found that the level of quality information provided on a website has an effect on a customer's evaluation of the website. Ludin and Cheng's (2014) research also found that websites should provide customers with informative and valuable information as this helps to reduce the amount of time searching for information or completing a task. Delaraso and Susilo (2013) also agree with Ludin and Cheng (2014) that online web providers ought to provide customers with up-to-date, useful, accurate and complete information in order to fulfill the information needs of customers.

The quality of information published online could potentially be poor due to no control mechanism, particularly when compared to printed publications (Rieh, 2002). Rieh (2010) suggests that with the growth of the Internet, we now see a mass of information with varying levels of quality. Thus, customers can use various techniques in order to analyse the quality of information online (Robson and Robison, 2015). Lucassen and Schraagen (2011) suggest that the level of evaluation that individuals' conduct is based on their level of skills. Three forms of information quality evaluations exist, semantic evaluations which are carried out by those will expertise within the subject area, surface evaluations which are based on heuristics and evaluating features of the website and its content and lastly, source evaluations which are focused on evaluating the authority of the website based on its perceived reputation. However, Guo et al (2012) and Rieh (2010) suggest that information quality evaluation is always based on heuristics, where customers refer to the surface characteristics of the website providing quick evaluations of the website. This is in line with Brehm's (1966) Psychological Reactance Theory, where past experiences create new expectations. Thus, should a customer have previous experience where a website conveys cues to quality information, this becomes an expectation for subsequent websites. As a result, the following hypothesis has been developed:

H2 Information quality cues positively influence search success. 


\section{Website Credibility}

Website credibility and information quality are often two variables that are discussed together (Rieh. 2010). A review of the literature acknowledges the intertwined nature of both variables (Lucassen and Schraagen, 2011; Metzeger, 2007). However, website credibility refers to the level of trustworthiness that the website conveys to its users (Fogg, 2003). Fogg and Tseng (1999) further comment that many studies confuse credibility with trust, where the terms are often used interchangeably without much consideration. However, Lucassen et al (2013) highlight that trust is the act of the user and on the other hand credibility is seen as the property of the information or subject (i.e. the website). Similar to evaluating the quality of the information, Lucassen (2013) outline the same three forms of credibility evaluation, firstly, semantic credibility, assessing how accurate and complete the information is, assessing factual accuracy. Secondly, surface credibility assessing the design, look and feel of the website, including the influence of spelling and grammatical mistakes. Lastly, source credibility, referring to the source of the information on the website, the brand of the website, accreditation associated with the website and links to such sources. However, those customers with little to no expertise within the subject area are unable to conduct a concise semantic credibility assessment due to the inability to assess the factual accuracy of the information provided by the website (Lucessen, 2013; Westerwick, 2013). Thus, Flanigan and Metzger (2007) suggest that website credibility is based on the surface characteristics of the website using heuristics (general rules of thumb) to assess the website's credibility. Therefore, the most common form of credibility assessment involves customers assessing the brand of the website, the look of the website, sources used on the website, accreditation and associations (Flanigan and Metzger, 2007; Fogg et al, 2001) which can all be conducted in a timely manner. Similar to assessing the quality of the information on the website, we can again look towards Brehm's (1966) Psychological Reactance Theory to understand customers' behaviour. Thus, those customers who have past experiences of a website that provides cues on the credibility of the website, becomes an expectation of customers for subsequent websites. As a result, the following hypothesis has been developed:

H3 Website credibility cues positively influence search success. 


\section{Customer Support}

While the credibility of the website and the quality of the information on the website remain as two variables that have been overlooked in relation to the online customer experience, online customer support has received little attention. Often regarded as one of the fundamental differences within online and offline service environments is the element of social interaction, i.e. synchronised two-way communication (Nass; Moon, 2000). Within the offline environment, customers interact with service personnel in a face-to-face manner in both B2B and B2C contexts and in some instances may even make an effort to maintain a relationship with key service staff particularly in the B2B context (Biedenbach and Marell, 2009; Macintosh and Lockshin, 1997). In the online environment, the experience is often comprised by the inaccessibility of service staff along with machine responses (Yang and Jun, 2002). Over recent years however, technological advancements through web 2.0 functionality and social media have enabled the development of a more interactive social environment that provides B2B, B2C and C2C communication (Renard, 2013). The introduction of online social functions has developed what we see as the 'social customer' raising the expectation on being able to communicate online (Greenberg, 2010).

Many service providers are now utilising technology in order to provide customer service and support online (McLean and Wilson, 2016). Research has shown that in the offline environment, encounters with other customers and with service staff have an influence on the customer's experience during and after the service encounter (Tombs and McColl-Kennedy, 2003). Tombs and McColl-Kennedy's (2003) research finds that social interactions can give rise to customer's emotions and emotional displays, which in turn can influence the individual's behaviour. Truel and Connelly (2013) discuss live chat technology that allows website users to seek 'service related information' from a real human representative who provide answers through the synchronous media. Additionally, Chattaraman et al (2012) highlight three key purposes of live chat technology, firstly to serve as a search support function, secondly to serve as a basic decision support function and thirdly to serve as a navigational/procedural support function. Such support as highlighted by Tombs and 
McColl-Kennedy (2003) is often required in the offline environment and subsequently has an effect on the customer's experience. Kuhlthau's (2004) work on the zone of intervention highlighted the importance of social interaction with others in order to move through the information search process. However, we have little understanding if a requirement for online customer support exists as well as the cognitive and affective emotions resulting from the lack of online customer support. Thus, the following hypothesis have been developed:

H4 An unsuccessful search is positively related to the requirement for online customer support

H5 The lack of online customer support is positively related to dissatisfaction with their experience.

\subsection{Methodology}

An online experiment was conducted on three selected B2B business advisory websites with a sample size of 195 participants. Each website offers businesses information on business growth, leadership, developing employees, funding, tax, legal matters and day-to-day advice on running a business. Participants were given 6 minutes to complete up to 3 tasks on each website, 18 minutes in total, with the experiment and questionnaire taking 36 minutes on average to complete. Participants could spend the full 6 minutes on one task, or complete two tasks or all three tasks. A pilot study was conducted to understand the average length of time it would take a respondent to complete the tasks and make an assessment on the websites.

Completing up to 3 tasks or spending a full 6 minutes provided the required exposure to assess the website. Participants were given a business scenario and information/services to find such as 'You are a software company in the UK, locate information on funding opportunities available for staff training' and 'Locate information on support for new biotechnology companies on how to comply with UK legislation'.

Using an online experiment provided each respondent with the experience of searching for business advisory services across three different business advisory 
websites, overcoming issues with self-recall of experiences. Data were collected through a web-based questionnaire immediately after the completion of each experiment. In order to test the hypothesised relationships, structural equation modelling (SEM) was adopted using AMOS Graphics 22. Due to the online questionnaires being researcher administered, all 195 responses were usable with no missing data, which is consistent with the sample required for SEM (Byrne, 2013). The benefit of structural equation modeling is that the hypothesised model can be tested statistically in a simultaneous analysis of the whole model of variables (Byrne, 2013). The sampling frame consisted of a mix of business owners $(\mathrm{n}=55)$ and postgraduate/undergraduate business students $(n=140)$ within the UK. The sample achieved a relatively even split between males (46\%) and females (54\%). In terms of age group, the study achieved a good representation of ages, 18-25 (27\%), 26-34 (27\%), 35-42 (24\%), 43-50 (18\%) and 50+ (4\%). On average participants were fairly knowledgeable and relatively confident at using the Internet.

\section{Measure Development}

The questionnaire consisted of 29 scale items measuring the variables of information quality, website credibility, customer support and the level of satisfaction with the experience. All scale items were measured on a 5-point Likert scale ranging from (1) Strongly Disagree to (5) Strongly Agree. In order to measure the customer experience, both an emotions scale and a scale on the level of satisfaction with the experience was used. This captures both the cognitive and affective aspect involved in the customer experience (see: Edvardsson, 2005). In line with McLean and Wilson (2016) the research acknowledges the time conscious nature of individuals during B2B information search. Thus, the session length for each task was recorded in order to aid in categorising successful or unsuccessful search during the search process. The average time for a successful search was worked out for each task (x3) in each experiment (x3). Those searchers who were faster than the average time to successfully complete the task were allocated 2 points. Those searchers who were slower than the average successful searcher were allocated 1 point and those who did not complete the task were allocated 0 points. In total the maximum number of points a participant could receive was 18 points ( 3 tasks $\mathrm{x} 3$ experiments). In order to work within a 5-point scale, like all other scales within the study, the total points for each 
participant was divided by 3.6. Using the recorded time for completing a successful search allowed the researcher to measure how successful a customer was in searching for their tasks. In addition, the researcher was able to observe and record the success of individuals obtaining the correct information in the search task. Thus, incorporating the time element as highlighted by McLean and Wilson (2016) and observing actual completions. See appendix 1 for all scale items and their corresponding sources.

\section{Preliminary Analysis}

In order to assess the appropriateness of the sample, a repeated measures ANOVA was conducted between business owners and postgraduate/undergraduate business students across the three experiments to identify if any differences existed between the responses of the two groups on the variables within the study. The results of this test showed that there was no significant difference between business people and business students, Wilks' Lambda $=.41, f(55.00,55.00)=1.82, \mathrm{p}=.19$. Therefore, the sample used in the study can be deemed as being appropriate. Additionally, a second repeated measures ANOVA was conducted to identify if any differences existed between the three websites used in the study. The results showed, Wilks' Lambda $=.21, f(20.00,175.00)=30.61, \mathrm{p}=.000$, which can therefore be concluded as a significant difference, $p=<.05$. As a result, this provides the study with a broad and representative set of websites that can produce generlisable results for business advisory providers. Furthermore, the study conducted MANOVA tests to assess for the potential influence of age, gender, usage of the Internet and confidence using the Internet. The results of the MANOVA tests showed no significant difference with regard to each control variable.

Scale reliability tests and data normality tests were conducted prior to structural modelling. In order to conduct reliability tests cronbach's alpha coefficient was calculated. The value for each scale was above the critical value of .7 (Pallant, 2013). Thus the scales offer discriminant validity. Appendix 1 outlines the Cronbach's alpha values. 


\section{Structural Equation Modelling}

Structural equation modelling is conducted in two steps, first the measurement model and second the structural model. The fit statistics of the CFA measurement model were $\operatorname{good}\left(\mathrm{x}^{2}=2.37, \mathrm{CFI}=.96, \mathrm{NFI}=.95, \mathrm{GFI}=.95, \mathrm{SRMR}=.04, \mathrm{RMSEA}=.04\right.$, $\mathrm{RMR}=.01)$. Further to the fit statistics all loadings were adequate and significant at $p$ $=.000$.

Thus, due to a good fitting measurement model, the study can proceed to the second step, which involves the specification and estimation of the hypothesised structural model. The fit statistics of the structural model showed goodness of fit with 5 degrees of freedom $\left(\mathrm{x}^{2}=2.61, \mathrm{CFI}=.97, \mathrm{NFI}=.96, \mathrm{GFI}=.97, \mathrm{SRMR}=.01, \mathrm{RMSEA}=.04\right.$, $\mathrm{RMR}=.01)$. Additionally, table 1 and figure 1 outline strong relationships.

\section{Table 1 Standardised Path Regression Weights}

\begin{tabular}{|c|c|c|c|c|c|}
\hline Hypotheses & & & & Estimates & Significance \\
\hline H1 & $\begin{array}{l}\text { Search } \\
\text { Success }\end{array}$ & $\rightarrow$ & $\begin{array}{l}\text { Level of Satisfaction } \\
\text { with the Experience }\end{array}$ & .67 & $\mathrm{p}<.001$ \\
\hline $\mathrm{H} 2$ & $\begin{array}{l}\text { Information } \\
\text { Quality }\end{array}$ & $\rightarrow$ & Search Success & .57 & $\mathrm{p}<.001$ \\
\hline H3 & $\begin{array}{l}\text { Web } \\
\text { Credibility }\end{array}$ & $\rightarrow$ & Search Success & .59 & $\mathrm{p}<.001$ \\
\hline $\mathrm{H} 4$ & $\begin{array}{l}\text { Search } \\
\text { Success }\end{array}$ & $\rightarrow$ & Seek Customer Support & -.32 & $\mathrm{p}<.001$ \\
\hline H5 & $\begin{array}{l}\text { Online } \\
\text { Customer } \\
\text { Support }\end{array}$ & $\rightarrow$ & $\begin{array}{l}\text { Level of Satisfaction } \\
\text { with the Experience }\end{array}$ & -.47 & $\mathrm{p}<.001$ \\
\hline $\begin{array}{l}\text { Non- } \\
\text { hypothesised }\end{array}$ & $\begin{array}{l}\text { Information } \\
\text { Quality }\end{array}$ & $\rightarrow$ & $\begin{array}{l}\text { Level of Satisfaction } \\
\text { with the Experience }\end{array}$ & .48 & $\mathrm{p}<.001$ \\
\hline $\begin{array}{l}\text { Non- } \\
\text { hypothesised }\end{array}$ & $\begin{array}{l}\text { Information } \\
\text { Quality }\end{array}$ & $\rightarrow$ & Online Customer Support & .44 & $\mathrm{p}<.001$ \\
\hline $\begin{array}{l}\text { Non- } \\
\text { hypothesised }\end{array}$ & $\begin{array}{l}\text { Web } \\
\text { Credibility }\end{array}$ & $\rightarrow$ & $\begin{array}{l}\text { Level of Satisfaction } \\
\text { with the Experience }\end{array}$ & .62 & $\mathrm{p}<.001$ \\
\hline $\begin{array}{l}\text { Non- } \\
\text { hypothesised }\end{array}$ & $\begin{array}{l}\text { Web } \\
\text { Credibility }\end{array}$ & $\rightarrow$ & Online Customer Support & .45 & $\mathrm{p}<.001$ \\
\hline
\end{tabular}


Figure 1 Structural Model

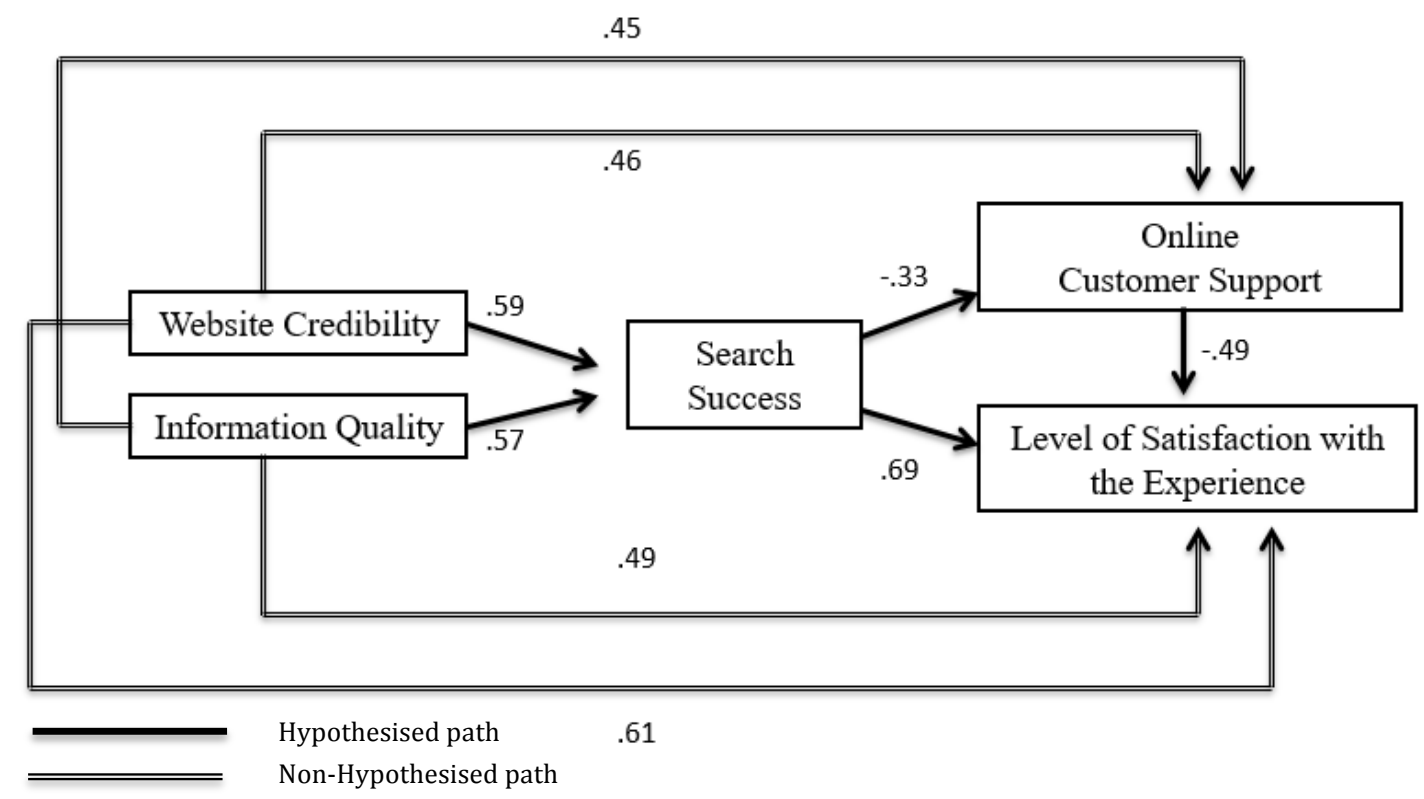

Significant relationships can be seen in table 1 and figure 1 in relation to the hypotheses previously outlined. All hypothesised relationships have been supported and show high regression weights all of which are significant at $p<.001$. Therefore, the study concludes that the proposed model with its mediating structure has supporting statistical and theoretical evidence. In addition, a number of additional relationships were identified with direct effects from Information Quality and Website Credibility on the Customer Experience and the need to seek Online Customer Support. To further investigate such effects, the recommended steps for mediation analysis as proposed by Zhao et al (2010) was followed. In addition to the Baron and Kenny analysis, the bootstrap test of the indirect effect was tested in AMOS Graphics. The results of the bootstrap test found that the indirect effects between all possible routes (Web Cred-SerSuc-OnlCustSup: WebCred-SerSuc-LevSatExp: InfoQualSerSuc-OnlCustExp: InfoQual-SerSuc-LevSatExp) are statistically significant $p=<$ .05 thus, highlighting the importance of the mediating role of search success. 


\subsection{Discussion}

\section{Theoretical implications}

The findings of the research establish that the variables of information quality and website credibility influence the customer experience during search for information on B2B websites. Previous research has focused on variables such as website aesthetics, involving the design and layout of the website as well as how easy the site is to use in relation to the customer experience (Martin et al, 2015; Rose et al, 2012). However, this research advances our knowledge and finds the utilitarian variables of the quality of the information on the website as well as the credibility of the website has a significant influence on the customer experience on B2B websites.

The results illustrate that the quality of the information on the website as well as the credibility of the website has a significant effect on the success of the search. Therefore, should customers perceive the website as being credible and containing good quality information, customers will have a successful search. Previous studies have often been unable to assess a customer's success in their search due to the deployed methodological approach. Due to this study adopting an online experiment to explore the phenomena, such a finding was achievable. Thus, it is noteworthy to acknowledge the importance of providing customers with cues on the quality of the information and the credibility of the website. Cues illustrating that the content is relevant, current and useful aid in highlighting quality information. This can be completed through testimonials on the website, case examples as well as time and date stamps next to information. In addition, source cues can be provided to enhance the quality of the information with information on the source of the information to support its accuracy. In terms of website credibility providers should ensure there are no broken links, no spelling or grammatical mistakes, the ability to contact the organisation, accreditation and credentials of the organisation, as well as professional design, which aid in providing credibility cues for website users and thus has a positive influence on the customer experience.

While the credibility of the website, along with the quality of the information on the website has an effect on the success of the search, each variable has a direct influence 
on the customer experience. Service providers that offer users a credible website with high quality information will have a positive effect on the customer experience, inducing positive emotions of confidence, being sure, relieved and satisfied with the experience. According to Flavian-Blanco et al (2011) positive emotions have a lasting effect on customers after the experience and thus influence re-visit intention of the website (Klaus, 2013). Therefore, it is important that close attention is paid to the credibility of the website and the quality of the information provided on B2B websites.

Further to this, table 1 highlights that the success of the search has an effect on the need to seek customer support. Customers who are able to navigate the website freely and find the information sought after do not require online customer support and thus will be satisfied with their experience. However, should customers be unable to find the information they require or have doubts over the information, there is a need to seek online customer support in order to aid them in their online search. The findings highlighted that customers would abandon their search if they were unable to seek online customer support. Tombs and McColl-Kennedy (2003) highlighted the need for customer support in the offline environment, where customers often seek the assistance of physical service staff, similarly this research has found that B2B customers operating in the online environment are no different, and thus should customers have an unsuccessful search a need exists for online customer support. This finding is further supported by Kuhlthau's (1996) Intervention Theory in the offline environment that illustrates individuals often require guidance and intervention during their search for information.

Interestingly, this study finds that while a customer may regard the credibility of the website as being positive, they may still require online customer support with a service representative. Respondents illustrated that this is due to not being able to find the information or services required. Similarly, the results show that should customers perceive the website as having good quality information, customers may still require online customer support, again due to being unable to find the information and services required and to further clarify the information. Thus, while the quality of the information is important to customers as well as the website being credible, this does not overcome the need for B2B websites to provide customers with online customer 
support. Should a search end in an unsuccessful manner, there is a need for online customer support to deliver the service recovery required in order to meet the customer's needs. Therefore, this further highlights the need for customer support in the online B2B environment. The web is often thought of as a self-service function, however based on the psychological reactance theory (Brehm, 1966), due to past experiences within the offline environment of having a service encounter with service staff aiding the customer during their service encounter, customers take this expectation into the online environment and expect the same level of service, thus should the customer have a question or a problem needing resolved customers expect to be able to communicate with service personnel. Moreover, the findings illustrate that a lack of online customer support results in customers becoming dissatisfied with their experience, provoking negative emotions of frustration, anxiety and disappointment. Thus, online customer support with a service representative may provide the service recovery required, avoiding customers from abandoning their search.

The findings further elaborate that the success of a search has a positive effect on the customer's experience. A strong relationship between a successful search and a positive customer experience was found. Therefore, it is important to acknowledge the variables of information quality and website credibility in order for customers to have a successful search resulting in a positive experience educing positive emotions and satisfaction with the experience.

This research finds that website credibility, information quality and online customer support play a role in relation to the customer experience. Information quality and website credibility have a direct effect on the customer experience as well as the success of a customer's search. The findings illustrated a need for online customer support despite positive perceptions towards the quality of the information and credibility of the website. In addition, the study outlined that the lack of online customer support through the ability to communicate with a service representative will result in customers becoming dissatisfied with their experience, highlighting the requirement of online customer support. 


\section{Managerial Implications}

This study offers managers of B2B websites numerous practical implications. The findings suggest that the quality of the information provided on the website as well as how credible the website appears to customers has an influence on the success of the customer's search. The quality of the information refers to the accuracy, relevance, how current and the usefulness of information provided on a website. Website credibility refers to the assessment of key surface characteristics of the site, including the ability to contact the organisation, checking accreditation or company credentials, the brand of the website, the URL and the websites aesthetics (the design of the site). Thus mangers and marketing professionals responsible for the provision of $\mathrm{B} 2 \mathrm{~B}$ websites ought to pay close attention to each of these variables in providing customers with a positive experience. Providing customers with cues on the credibility of the website will enhance the customer's experience, thus a well-designed website, supported with company credentials and accreditation, information on the brand and the ability for customers to contact the company help to enhance the credibility of the website. In addition, providing cues on the accuracy, relevance and how current the information is with time and date stamps, links to sources aids in providing a website that informs customers on the quality of the information provided on the website. Respondents illustrated that important business decisions may be made from the services provided on the service provider's website, therefore the credibility of the website and the quality of the information become of upmost importance to the customer in a B2B context. The results show that not only does information quality have a direct effect on the success of the customer's task but also on the overall customer experience. Previous research has highlighted the outcomes of a positive customer experience including re-visit intention, trust and loyalty, thus it is important that close attention is paid to providing customers with credibility and information quality cues.

As has been previously discussed, a distinctive difference between the online and offline environment is the ability to socially interact with a customer representative. However, with the advancements of recent technology, new features such as live chat technology and online customer helpdesks allow organisations to offer synchronised online customer support. The research findings suggest that online customer support 
is required via synchronised communication with a service representative when the customer is unable to successfully complete their tasks on a B2B website. A customer's requirement of online support informs managers that customers are not encountering a positive experience and are unable to find the information or services required. However, online customer support can act as a service recovery tool for B2B website providers. Therefore, a further implication for managers of B2B websites is to provide customers with online support. Simply providing customers with information and self-service functions may be a disservice to customers. An introduction of online customer support will help to prevent customers abandoning their search.

While providing cues to illustrate the credibility of the website as well as the quality of the information is important, customers may still require online customer support despite a website that appears to contain quality information and an overall credible website. Therefore, the implementation of a live chat system or online help desk is an important implication for B2B website providers, the absence of such a customer support function will increase the abandonment rate of the website and negatively affect the customer's experience.

\subsection{Limitations and recommendations for future research}

The findings and the contributions of this study are somewhat constrained by certain limitations, of which opportunities for future research arise. This study focused on website credibility and information quality, it would be insightful to establish if the variables of website aesthetics, ease of use and the much discussed concept of flow from research on $\mathrm{B} 2 \mathrm{C}$ websites have any influence on the customer experience within B2B websites. Additionally, the model is somewhat saturated with the additional nonhypothesised parameters in the model. Future research could establish a wider B2B customer experience model.

While this research has found that online customer support is required if a customer has an unsuccessful search. It would valuable for future research studies to explore if a role for online customer support exists within other B2B contexts beyond searching for information/services and examining online support through the purchase process. 


\section{Appendix 1}

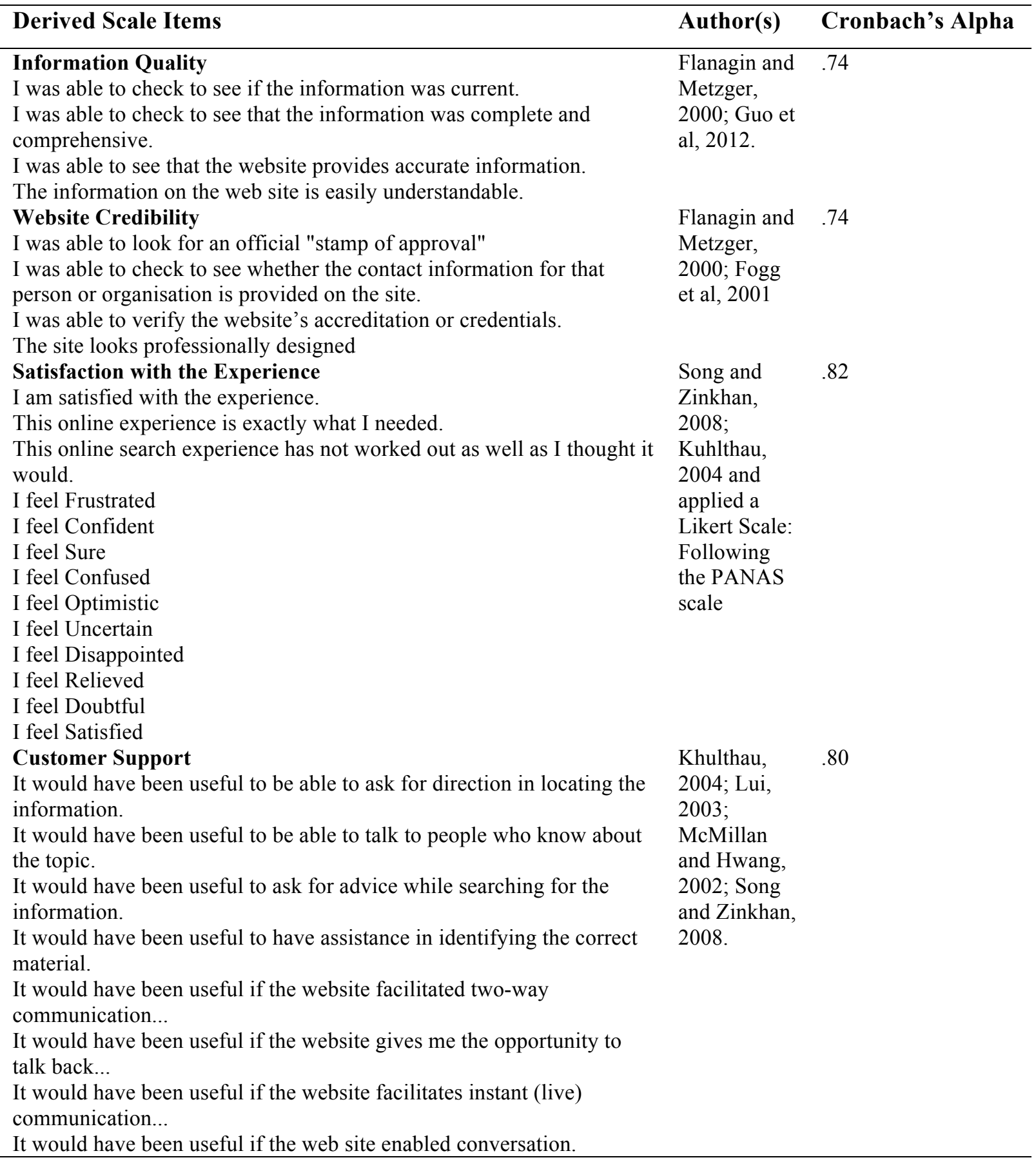




\section{References}

Ahmed, R. I. (2011): 'Experience Marketing: An Empirical Investigation', Journal of Relationship Marketing, 10, pp.167-201.

Alexa (2017) 'Complete web analytics toolkit'. Available From http://www.alexa.com Accessed 14/03/2017.

Biedenbach, G., and Marell, A. (2009) The impact of customer experience on brand equity in a business-to-business service setting, Brand Managemet, 17, 6, 446-458.

Bigne, J. E., Anna, S., \& Andreu, M. L. (2008): 'The impact of experiential consumption cognitions and emotions on behavioural intentions'. Journal of Services Marketing, 22, pp.303-315.

Brehm, J. (1996): A theory of psychological reactance. New York (NY): Academic Press.

Brodie, R. J., Ilic, A., Juric, B., \& Hollebeek, L. (2013): 'Consumer Engagement in a Virtual Brand Community: An Exploratory Analysis'. Journal of Business Research, 6, pp.105-114.

Byrne, B. M. (2013): 'Structural Equation Modelling with AMOS Graphics. $3^{\text {rd }}$ Ed. Routledge, New York.

Carbone, L. P., \& Stephan, H. H. (1994): 'Engineering Customer Experiences', Marketing Management, 3, 3, pp.9-11.

Chattaraman, V., \& Kwon, W. S., \& Gilbert, J. E. (2012): 'Virtual agents in retail web sites: Benefits of simulated social interaction for older users'. Computers in Human Behavior, 28, pp.2055-2066.

Churchill, G. A. (1979): 'A paradigm for developing better measures of marketing constructs', Journal of Marketing Research, 16, 1, pp.64-73.

Ding, D. X., Hu, P. J. H., Verma, R. \& Wardell, D. G. (2009): 'The Impact of Service Design and Flow Experiences on Customer Satisfaction in Online Financial Services'. Journal of Services Research, 13, pp.96-110.

Edvardsson, B. (2005): 'Service Quality: Beyond congnitve assessment'. Managing Service Quality, 15, 2, pp.127-131.

Edvardsson, B., \& Gustafsson, A. \& Roos, I. (2005): 'Service portraits in service research - a critical review'. International Journal of Service Industry Management, $16,1, \mathrm{pp} .107-121$.

Engel, J. F., Blackwell, R., \& Kollat, D. T. (1978): Consumer Behaviour, $3^{\text {rd }}$ ed. Hinsdale, IL: Dryden. 
Faiola, A., Newlon, C., Pfaff, M., \& Smyslova, O. (2013): 'Correlating the effects of flow and telepresence in virtual worlds: Enhancing our understanding of user behaviour in game-based learning'. Computers in Human Behaviour, 29, pp.11131121.

Flanagin, A, J. and Metzger, M. J. (2007) The role of the sites features, user attributes, and information verification behaviours on the perceived credibility of web-based information, New Media and Society, 9, 2, 319-342.

Flavian-Blanco, C., Gurrea-Sarasa, R. \& Orus-Sanclemente, C. (2011): 'Analyzing the emotional outcome of the online search behaviour with search engines'. Computers in Human Behaviour, 27, pp.540-551.

Fogg, B. J. (2003) Prominence-Interpretation-Theory: Explaining how people assess credibility online, Trust, Security and Safety, 722-723.

Gentile, C., \& Spiller, N., \& Noci, G. (2007): 'How to sustain the customer experience: An overview of experience components that co-create value with the customer'. European Management Journal, 25, 5, pp.395-410.

Greenberg, P. (2010): 'The impact of CRM 2.0 on customer insight'. Journal of Business \& Industrial Marketing, 25, pp.410-419.

Ha, H. L., Swinder, J. \& Siva, K. M. (2010): 'A New Under- standing of Satisfaction Model in E-re-purchase Situation'. European Journal of Marketing, 44 (7/8), pp.9971016.

Hilligoss, B., \& Rieh, S. Y. (2008): 'Developing a Unifying Framework of Credibility Assessment: Construct, Heuristics, and interaction in context'. Information Processing and Management, 44, pp.1467-1484.

Hoffman, D. L., \& Novak, T. P. (2009): 'Flow Online: Lessons Learned and Future Prospects'. Journal of Interactive Marketing, 23, pp.23-34.

Kaplan, A. M., \& Haenlein, M. (2010): 'Users of the world, unite! The challenges and opportunities of social media'. Business Horizons, 53, pp.59-68.

Kuhlthau, C. C. (1991): 'Inside the Search Process: Information Seeking from the User's Perspective'. Journal of The American Society for Information Science, Vol. 42, No. 5, pp.361-371.

Kuhlthau, C. C. (2004): Seeking meaning: a process approach to library and information services, $2^{\text {nd }}$ Edition, Libraries Limited, Westport.

Khalifa, M. \& Liu, V. (2007): 'Online Consumer Retention: Contingent Effects of Online Shopping Habit and Online Shopping Experience', European Journal of Information Systems, 16, 6, pp.780-92.

Lee, A. S., \& Jeong, M. (2010): 'Effects of e-servcescape on customers flow experiences'. Journal of Hospitality and Tourism Technology, 3, pp.47-59. 
Liu, Y., \& Shrum, L. J. (2002): 'What Is Interactivity and Is It Always Such a Good Thing? Implications of Definition, Person, and Situation for the Influence of Interactivity on Advertising Effectiveness'. Journal of Advertising, 31, pp.53-64.

Lucassen, T., and Schraagen, J.M.C. (2011). Factual accuracy and trust in information: The role of expertise, Journal of the American Society of Information Science and Technology, 62, 7, 1232-1242.

Lucassen, T., Muilwijk, R., Noordzij, M. L., and Schraagen, J, M. (2013) Topic familiarity and information skills in online credibility evaluation, Journal of The American Society For Information Science and Technology, 64, 2, 254-264.

Ludin, I. H. B., \& Cheng, B. L. (2014): 'Factors influencing customer satisfaction and e-loyalty: Online shopping environment among young adults'. Management Dynamics in the Knowledge Economy, 2, 3, pp.462-471.

Luo, M., M., Chen, J. S., Ching, R. K. H., \& Liu, C. C. (2011): 'An Examination of the Effects of Virtual Experiential Marketing on Online Customer Intentions and Loyalty'. The Services Industries Journal, 31, pp.2163-2191.

Macintosh, G., \& Lockshin, L.S. (1997): 'Retail relationships and store loyalty: a multi-level experience', International Journal of Research in Marketing, 14, 5, pp.487-97.

Mathwick, C. (2005): 'The effect of playful web experiences on brand attitude formation'. Advances in Consumer Research, 32, pp.65-65.

Martin, J., Mortimer, G., and Andrews, L. (2015) 'Re-examining online customer experience to include purchase frequency and perceived risk'. Journal of retailing and consumer services, 25, 81 - 95.

McLean, G. and Wilson, A. (2016) Evolving the online customer experience.... is there a need for online customer support, Computers in Human Behaviour, 60, 602-610.

McMillan, S. J., \& Hwang, J. S. (2002): 'Measures of perceived interactivity: an exploration of the role of direction of communication, user control, and time in shaping perceptions of interactivity'. Journal of Advertising, 31, pp.29-42.

Mayfield, A. (2008): What is social media?. UK: iCrossing. e-Book. Retrieved from http://www.icrossing.co.uk/fileadmin/uploads/eBooks/What is_Social_Media_iCross ing e book.pdf.

Meyer, C., \& Schwager, A. (2007): 'Understanding Customer Experience'. Harvard Business Review, 85, 2, pp.116-126.

Mollen, A., \& Wilson, H. (2010): 'Engagement, Telepresence and Interactivity in online consumer experience: Reconciling Scholastic and Managerial Perspectives'. Journal of Business Research, 63, pp.919-925.

Nass, C., \& Moon, Y. (2000): 'Machines and Mindlessness: Social Responses to Computers'. Journal of Social Issues, 56, pp.81-103. 
Novak, T. P., \& Hoffman, D. L., \& Yung, Y. F. (2001): 'Measuring the customer experience in online environments: A structural equation approach'. Marketing Science, 19, 1, pp.22-42.

O'Reilly, T. (2005): 'What is web 2.0: Design patterns and business models for the next generation of software'. Available from http://www.oreillynet.com/pub/a/ oreilly/tim/news/2005/09/30/what-is-web-20.html Accessed 20.11.2014.

Rafaeli, S. (1988): Interactivity: From New Media to Communication, in Advancing Communication Science: Merging Mass and Interpersonal Processes, R.P. Hawkins, J.M. Wiemann, and S. Pingree, eds. Newbury Park, CA: Sage Publications, pp.11034.

Renard, D. (2013): 'Online Promotional Games: Impact of Flow Experience on Word-of-Mouth and Personal Information Sharing'. International Business Research, 6, pp.93-100.

Rose, S., Clark, M., Samouel, P., \& Hair, N. (2012): 'Online Customer Experience in e-Retailing: An empirical model of Antecedents and Outcomes'. Journal of Retailing, 88, pp.308-322.

Savolainen, R. (2015) The interplay of affective and cognitive factors in information seeking and use, Journal of Documentation, 71, 1, 175 - 197.

Schmitt, B. (1999): 'Experiential Marketing'. Journal of Marketing Management, 15, pp.53-57.

Shobeiri, S., Mazaheri, E., Laroche, M. (2014): 'Improving Customer Website Involvement Through Experiential Marketing'. The Services Industries Journal, 34, pp.885-900.

Song, J. H., \& Zinkhan, G. (2008): 'Determinants of Perceived Web Site Interactivity'. Journal of Marketing, 72, pp.99-113.

Tabachnick, B. G., \& Fidell, L. S. (2007): 'Using multivariate statistics'. $5^{\text {th }}$ Ed. Boston: Allyn and Bacon.

Trevinal, A. M., and Stenger, T. (2014) 'Toward a conceptualisation of the online shopping experience'. Journal of Retailing and Consumer Services. 21, 314 -326.

Truel, O., \& Connelly, C.E. (2013): 'Too busy to help: Antecedents and outcomes of interactional justice in web-based service encounters'. International Journal of Information Management, 33, pp.674-683.

Tombs, A., \& McColl-Kennedy, J. R. (2003): 'Social-servicescape conceptual model'. Marketing Theory, 3, 4, pp.447-475.

Van Noort, G., Voorveld, H. A. M., \& Van Reijmersdal, E. A. (2012): 'Interactivity in Brand Web Sites: Cognitive, Affective and Behavioral Responses Explained by Consumers' Online Flow Experience'. Journal of Interactive Marketing, 26, pp.223234. 
Verhoef, P., Lemon, K., Parasuraman, A., Roggeveen, A., Schlesinger, L. \& Tsiros, M. (2009): 'Customer experience: determinants, dynamics and management strategies', Journal of Retailing, 85, 1, pp.31-41.

Wang, Y. J., Hernandez, M. D., \& Minor, M. S. (2010): 'Web Aesthetics effects on percieved online service quality and satisfaction in an e-tial environment: The moderating role of purchase task'. Journal of Business Research, 63, pp.935-942.

Westerwick, A. (2013) Effects of sponsorship, Website design and Google ranking on

the credibility of information, Journal of Computer-Mediated Communications, 18 , 194-211.

Whetten, D. A. (1989): 'What Constitutes a Theoretical Contribution?'. Academy of Management Review, 14, pp.490-495.

Wu, L. L., Wang, Y. T., Wei, C. H., \& Yeh, M. Y. (2013): 'How Interactivity Works for Utilitarian and Hedonic Consumers Online'. 46th Hawaii International Conference on System Sciences, pp.2881-2890.

Yang, Z., \& Jun, M. (2002): 'Consumer perception of e-service quality: from Internet purchaser and non-purchaser perspectives', Journal of Business Strategies. 19, 1, pp.19-41.

Zhao, X., Lynch Jr, J. G., Chen, Q. (2010) Reconsidering Baron and Kenny: Myths and Truths about Mediation Analysis, Journal of Consumer Research, 37, 2, pp.197206. 